\title{
Development of Film Forming Agent HN-1 and Its Application in Drilling Fluid
}

\author{
Youlin Hu \\ College of Petroleum Engineering, Yangtze University, Jingzhou, China \\ Email: 61872218@qq.com
}

Received June 14, 2013; revised July 14, 2013; accepted July 21, 2013

Copyright (C) 2013 Youlin Hu. This is an open access article distributed under the Creative Commons Attribution License, which permits unrestricted use, distribution, and reproduction in any medium, provided the original work is properly cited.

\begin{abstract}
Borehole instability and reservoir damage had become the international technical problems of petroleum exploration and development of complicated area, and the water of drilling fluid invading borehole wall and petroleum reservoir was the main cause of borehole instability and reservoir damage. In order to prevent the water of drilling fluid invading borehole wall and petroleum reservoir, domestic and foreign scholars recently put forward the technology of ultra-low permeable drilling fluid. Film forming agent was the key treating agent of ultra-low permeable drilling fluid, the film forming agent (HN-1) was developed, which did not affect properties of the drilling fluid and could decrease the filter loss of drilling fluid applied in Enping 24-2 oil field. Based on this research, ultra-low permeable drilling fluid could be applied to Enping 24-2 oil field. By the methods of testing ultra-low permeable drilling fluid properties, the drilling fluid invasion sand-bed depth, drilling fluid high temperature/high pressure (HTHP) sand-bed filter loss, the pressurebearing ability of rock core and the ability of reservoir protection were studied. By synergistic effect, HN-1 containing the organic silicate and natural fiber polymer modified by organic amine prevented the liquid and solids in drilling fluid invading reservoir, decreased drilling fluid invasion sand-bed depth and drilling fluid HTHP sand-bed filter loss, improved the pressure-bearing ability of rock core and the ability of reservoir protection. The drilling fluid could decrease reservoir damage to the maximal degree, and it offered efficiency guarantee for exploitation Enping 24-2 oil field.
\end{abstract}

Keywords: Ultra-Low Permeable; Film Forming Agent; Drilling Fluid; Reservoir Protection

\section{Introduction}

With the continuous extension of petroleum exploration and development, formation encountered during drilling operation became more and more complicated. Borehole instability and reservoir damage had become the international technical problems of petroleum exploration and development when drilling in the pressure depletion formation, the fracture development formation, the broken or weak cementation formation, low permeability reservoir, deep, long open hole, large-section and complicated shale and multiple pressure layers formation. The water of drilling fluid invading borehole wall and petroleum reservoir was the main cause of borehole instability and reservoir damage. The main manifestation of borehole instability was water invading borehole wall induced well-bore collapse and reservoir damage. To stabilize borehole and protect reservoir, liquid should be effectively prevented from invading formation. Physical blockage was mainly adopted to prevent water from invading formation in the world at present, but physical blockage had obvious limitation because it can not prevent liquid from invading formation pores and micro-fractures pertinently. Domestic and foreign scholars recently put forward chemical blockage method, which improved sidewall rock film forming efficiency and formed partition film in petroleum reservoir at the same time. It can make the formation water flow from formation to shaft by regulating the seepage pressure difference between two sides of the film, which prevented the liquid and the solids invading borehole wall and petroleum reservoir, thus achieving the goal of stabilizing borehole and protecting reservoir [1-8]. The ultra-low permeable drilling fluid was a breakthrough for drilling fluid in foreign countries recently, ultra-low permeable drilling fluid was widely applied in America, Argentina, Indonesia, Mexico, etc. and better effects of preventing borehole collapsed and reservoir protection were obtained.

\section{The Feature and Mechanism of Ultra-Low Permeable Drilling Fluid}

Ultra-low permeable drilling fluid not only had excellent 
properties of the conventional drilling fluid, but also had superior properties which the conventional drilling fluid did not have. The feature of its properties was as follows: 1) Unique principle of surface chemistry. According to the unique principle of surface chemistry, very thin filter cake which improved formation fracture pressure was formed when the drilling fluid penetrated into microfractures or pore throat on the surface of sidewall rock; 2) Low dynamic filter loss. The drilling fluid decreased the depth of its filtrate penetration rock by sealing formation fractures and pores; 3) Formation sealing film. Small particles of the drilling fluid formed sealing film in permeability or micro fractures formation, and adhered to sidewall under differential pressure; 4) High permeability recovery. Filter cake ultra-low permeable drilling fluid formed 98\% - 99\% could be cleared, and could fall off automatically in the case of pressure inversion. Core permeability recovery value was over $95 \%$, which was beneficial to improve production. Compared with conventional drilling fluid, ultra-low permeable drilling fluid was beneficial to improve stress sensitivity formation bearing pressure, protect reservoir, as well as its wide formation adaptability $[9,10]$.

Ultra-low permeable drilling fluid formed micelle on the surface of sidewall rock by means of special treating agent, and sealed larger pore throat on the surface of rock depending on interface suction and deformability of polymeric micelle. The drilling fluid formed compact ultra-low permeable sealing film which effectively sealed different permeability formation and micro-fractures shale formation, and formed cover on the peripheral sidewall. The drilling fluid and its filtrate would not penetrate to the deep formation, and its filtrate could be close to zero. The drilling fluid prevented the clay grains from migrating, decreased reservoir damage, protected reservoir effectively $[11,12]$.

\section{The Composition of Film Forming Agent}

Ultra-low permeable drilling fluid possessed semipermeable membrane performance, formed a layer partition membrane on sidewall, formed cover on the peripheral sidewall, prevented the liquid and solids in the drilling fluid invading the formation, prevented the formation from hydration swelling and borehole collapse, protected reservoir effectively.

The key treating agent of ultra-low permeable drilling fluid was film forming agent. By laboratory experiments, the film forming agent ( $\mathrm{HN}-1)$ was developed, which could rapidly form sealing film, decrease the filter loss of drilling fluid, improve sandstone bearing pressure [13, 14].

The film forming agent (HN-1) was developed by complex formulation of organic silicate and natural fiber polymer modified by organic amine according to proportion. The organic silicate could significantly improve the membrane efficiency of shale, and the natural fiber polymer modified by organic amine could rapidly form imperforation partition membrane on the sidewall. By synergistic effect, the organic silicate and natural fiber polymermodified by organic amine effectively prevented the liquid and solids in drilling fluid from invading formation, solved the technical problems such as hole collapse, leakage, sticking, reservoir damage, under complex conditions during drilling.

\section{The Properties of Ultra-Low Permeable Drilling Fluid}

\subsection{The Ultra-Low Permeable Drilling Fluid}

The well EP24-2-1, the well EP24-2-2 was respectively wildcat and evaluation well of Enping 24-2 oil field, the drilling operation of these two wells was smoothly, which showed that $\mathrm{KCl} / \mathrm{PLUS}$ drilling fluid was applied to these two wells could be applied to drilling operation of Enping 24-2 oil field. The reservoir lithology of Enping 24-2 oil field mainly was fine to medium grain feldsparthic lithic, feldsparquartz sandstone. The reservoir physical property of Enping 24-2 oil field was better, with medium to high pore, with medium to super high permeability, with unconsolidated payzones, and mainly with pore cementation. The reservoir was with medium to strong velocity sensitivity, water sensitivity, alkaline sensitivity, stress sensitivity. Combined with the feature of Enping 24-2 oil field reservoir, in order to prevent quid and solids in drilling fluid invading formation and effectively protect the reservoir, film forming agent must be added into non-reservoir drilling fluid to improve sealing ability before reservoir drilling.

The $\mathrm{KCl} / \mathrm{PLUS}$ drilling fluid formulation for Enping 24-2 oil field non-reservoir was as follows: 3\% (wt/vol) seawater bentonite mud $+0.1 \%$ (wt $/ \mathrm{vol}) \mathrm{NaOH}+0.15 \%$ (wt/vol) $\mathrm{Na}_{2} \mathrm{CO}_{3}+0.3 \%$ (wt/vol) PLUS (partially hydrolyzedpolyacrylamide) $+0.3 \%$ (wt/vol) LV-PAC (polyanionic cellulose $)+0.05 \%$ (wt/vol) XC (xanthan) $+2 \%$ (wt/vol) FLOcat (modified starch) $+1.5 \%$ (wt/vol) TEX (alphalt, antisloughing agent) $+1.5 \%$ (vol/vol) LUBe (lubricant) $+2 \%$ (wt/vol) $\mathrm{KCl}$. Based on the formulation, film forming agent (HN-1) was added into the drilling fluid to make it transform into ultra-low permeable drilling fluid. The ultra-low permeable drilling fluid formulation was developed in the laboratory for Enping 24-2 oil field. $3 \%$ seawater bentonite mud $+0.1 \% \mathrm{NaOH}+0.15 \%$ $\mathrm{Na}_{2} \mathrm{CO}_{3}+0.3 \%$ PLUS $+0.3 \%$ LV-PAC $+0.05 \%$ XC + $2 \%$ FLOcat $+1 \%$ SMP $+1.5 \%$ TEX $+1.5 \%$ LUBe + $1.5 \%$ (wt/vol) $\mathrm{HN}-1$ (film forming agent) $+2 \% \mathrm{KCl}$. The non-reservoir drilling fluid was prepared as follows: $\mathrm{NaOH}$ and $\mathrm{Na}_{2} \mathrm{CO}_{3}$ were added in the seawater. PLUS, 
LV-PAC, and $\mathrm{XC}$ were added in the mixture-under stirring at a rate of $800 \mathrm{r} / \mathrm{min}$. After stirring for $20 \mathrm{~min}$, FLOcat, SMP, $1.5 \%$ TEX, LUBe, and $\mathrm{KCl}$ were added. After fully stirring the mixture, bentonite mud was added, and continuously stirring for $20 \mathrm{~min}$, ultrafine calcium carbonate was added to adjust the fluid density to 1.15 $\mathrm{g} / \mathrm{cm}^{3}$ and then the drilling fluid was stirred for $20 \mathrm{~min}$. The ultra-low permeable drilling fluid was preparedas follows: $\mathrm{HN}-1$ was added in the non-reservoir drilling fluid, and then the drilling fluid was stirred for $20 \mathrm{~min}$. The rheological properties, and filter loss of the non-reservoir drilling fluid and the ultra-low permeable drilling fluid were measured following the standard procedures (GB/T 16783.1-2006, China) aged at $80^{\circ} \mathrm{C}$ for $16 \mathrm{~h}$, and listed in Table 1. High temperature/high pressure (HTHP) filter loss tests were performed at $80^{\circ} \mathrm{C}$ and $3.5 \mathrm{MPa}$. The results showed that $\mathrm{HN}-1$ hardly influenced the rheological properties of the non-reservoir drilling fluid and decreased the filter loss.

\subsection{Invasion Sand-Bed Depth}

Filter paper usually was adopted as isolation medium to measure the filter loss of drilling fluid, which could not accurately reflect the actual condition of formation because the filter paper was homogeneous and the formation was heterogeneous. Visual FA model nonfiltration filtration device whose structure was similar to the conventional filtration device was adopted to measure the filter loss of drilling fluid and the depth of drilling fluid filtrate invasion rock core, the main difference was sand-bed instead of filter paper as isolation medium. The depth of Enping 24-2 oil field non-reservoir drilling fluid and ultra-low permeable drilling fluid invasion sand-bed was studied by visual FA model non-filtration filtration device. $350 \mathrm{~cm}^{3}$ cleaning and dryings and (the particle size was 0.45 to $0.90 \mathrm{~mm}$ ) was added into cylinder, after compacting and spreading the even sand-bed, $500 \mathrm{~mL}$ drilling fluid was added slowly. By the method of measuring API filtrate, the pressure was adjusted to $0.69 \mathrm{MPa}$, and the depth of 30 minutes invasion sand-bed was measured [13].

The depth of non-reservoir drilling fluid invasion sand-bed was $9 \mathrm{~cm}$, but the depth of ultra-low permeable drilling fluid invasion sand-bed was $5 \mathrm{~cm}$.

\subsection{High Temperature/High Pressure (HTHP) Sand-Bed Filter Loss}

$200 \mathrm{~g}$ cleaning and drying sand (the particle size was 0.45 to $0.90 \mathrm{~mm}$ ) was added into the bottom of GGS71A model HTHP filter press, and $300 \mathrm{~mL}$ the non-reservoir drilling fluid and the ultra-low permeable drilling fluid prepared was added after compacting and spreading the even sand-bed, the drilling fluid 30 minutes HTHP sand-bed filter loss was measured, HTHP filter sand-bed filter loss tests were performed at $80^{\circ} \mathrm{C}$ and $3.5 \mathrm{MPa}$, experimental results were shown in Table 2, HTHP sand-bed filter loss decreased when $1.5 \% \mathrm{HN}-1$ was added into the non-reservoir drilling fluid. The results showed that HN-1 had good ability of sealing sand-bed under high temperature/high pressure.

\subsection{The Pressure-Bearing of Rock Core}

The experimental procedure was preformed as follows: the rock core from Enping 24-2 oil field was installed in HTHP core holder, drilling fluid prepared was added into the drilling fluid container. After the rock core and the drilling fluid being heated to $80^{\circ} \mathrm{C}$, the pressure HTHP core holder and constant-flux pump respectively was 4.2 $\mathrm{MPa}$ and $0.7 \mathrm{MPa}$. By the method of measuring HTHP filtrate, the 30 minutes filter loss was measured, if the filter loss was 0 , took down the rock core and measured the depth of filtrate invasion rock core. The rock core whose surface cake has been cleared was reinstalled in

Table 1. The basic properties of the drilling fluid.

\begin{tabular}{|c|c|c|c|c|c|c|c|c|}
\hline Drilling fluid system & $\begin{array}{l}\text { Density } \\
\rho, \mathrm{g} / \mathrm{cm}^{3}\end{array}$ & $\begin{array}{c}\text { Apparent viscosity } \\
\text { AV, } \mathrm{mPa} \cdot \mathrm{s}\end{array}$ & $\begin{array}{l}\text { Plastic viscosity } \\
\text { PV, mPa.s }\end{array}$ & $\begin{array}{c}\text { Yield } \\
\text { point } \\
\text { YP, Pa }\end{array}$ & Ф 6/Ф 3 & $\begin{array}{l}\text { Gel strength } \\
10^{\prime \prime} / 10^{\prime}, \mathrm{Pa}\end{array}$ & $\begin{array}{l}\text { API filtrate } \\
\mathrm{mL} / 30 \mathrm{~min}\end{array}$ & $\begin{array}{l}\text { HTHP } \\
\text { filtrate } \\
\mathrm{mL} / 30 \mathrm{~min}\end{array}$ \\
\hline $\begin{array}{l}\text { The non-reservoir } \\
\text { drilling fluid }\end{array}$ & 1.15 & 31 & 22 & 9 & $4 / 3$ & $2 / 3.5$ & 4.2 & 9.6 \\
\hline $\begin{array}{l}\text { The ultra-low permeable } \\
\text { drilling fluid }\end{array}$ & 1.15 & 33 & 23 & 10 & $4 / 3$ & $2 / 3.5$ & 3.6 & 8.4 \\
\hline
\end{tabular}

Table 2. The HTHP sand-bed filter loss of drilling fluid.

\begin{tabular}{cc}
\hline Drilling fluid system & $\begin{array}{c}\text { HTHP sand-bed filter loss, } \\
\mathrm{mL} / 30 \mathrm{minutes}\end{array}$ \\
\hline The non-reservoir drilling fluid & 4.6 \\
The ultra-low permeable drilling fluid & 0 \\
\hline
\end{tabular}


HTHP core holder, at the same time the formation water was instead of drilling fluid in the drilling fluid container and the constant-flux pump was started, the constant-flux pump was pressurized gradually to droplet outflow, the pressure was as the maximum bearing pressure of rock core [15-19]. According to the procedure, the maximum bearing-pressure of rock core rock which was invaded by the non-reservoir drilling fluid and the ultra-low permeable drilling fluid were studied, experimental results were shown in Table 3. HN-1 formed partition membrane on the surface of rock core from Enping 24-2 oil field, sealed pore throat on the surface of the rock core, decreased the filter loss, improved bearing pressure of rock core.

\subsection{The Ability of Reservoir Protection}

According to the petroleum industry standard of "Lab testing method of drilling and completion fluids damageing oil formation" (SY/T 16540-2002, China), the ability of Enping 24-2 oil field reservoir protection of the ultra-low permeable drilling fluid was evaluated with JHDS HTHP dynamic filter press and core permeability testing instrument. The rock core was contaminated backward for 125 minutes, the backward contamination was performed at $80^{\circ} \mathrm{C}, 3.5 \mathrm{MPa}$ and at the shear rate of $300^{-1}$. The permeability of the contaminated rock core was tested after backward displacement, and permeability recovery value was calculated. After the resection of one end contaminated of the rock core, the permeability of it was retested. If the permeability recovery value was over $95 \%$, the resection length of the rock core was the depth of drilling fluid filter invasion rock core, both the two experimental rock cores were from Enping 24-2 oil field, experimental results were shown in Table 4. The ultra-low permeable drilling fluid had good ability of reservoir protection, the permeability recovery value of the two rock core contaminated was both over $90 \%$. The depth of the drilling fluid filter invasion rock core was shallow, the permeability recovery value of the two rock core was both over $95 \%$ after the resection $0.5 \mathrm{~cm}$ contaminated end, the results were shown in Table 4. The ultra-low permeable drilling fluid formed protective layer on the surface of rock core, which prevented the drilling fluid and its filtrate from penetrating to the deep rock core, prevented the clay grains from migrating, decreased reservoir damage, and protected reservoir effectively.

\section{Conclusion}

The ultra-low permeable drilling fluid was beneficial to improving stress sensitivity formation bearing pressure, and protecting reservoir, as well as its wide formation adaptability. The film forming agent (HN-1) was developed by complex formulation of organic silicate and natural fiber polymer modified by organic amine according to proportion. By synergistic effect, the organic silicate and the natural fiber polymer modified by organic amine could form partition membrane on the sidewall, which prevented the liquid and solids in drilling fluid from invading formation. HN-1 did not affect properties of the drilling fluid, which rapidly forms sealing membrane, decreased the filter loss of drilling fluid, the drilling fluid invasion sand-bed depth, and drilling fluid HTHP sand-bed filter loss, and improved the ability of drilling fluid sealing and bearing-pressure of rock core. The depth of the ultra-low permeable drilling fluid filter invasion rock core from Enping 24-2 oil field was shal-

Table 3. The pressure-bearing of rock core.

\begin{tabular}{ccc}
\hline $\begin{array}{c}\text { Drilling fluid system } \\
\begin{array}{c}\text { The non-reservoir } \\
\text { drilling fluid }\end{array}\end{array}$ & $\begin{array}{c}\text { Filter loss, } \\
\mathrm{mL} / 30 \mathrm{minutes}\end{array}$ & $\begin{array}{c}\text { The maximum bearing-pressure } \\
\text { of rock core rock, } \\
\mathrm{MPa}\end{array}$ \\
\hline $\begin{array}{c}\text { The ultra-low permeable } \\
\text { drilling fluid }\end{array}$ & full invasion & 0.2 \\
\hline
\end{tabular}

Table 4. The reservoir protection of the ultra-low permeable drilling fluid.

\begin{tabular}{|c|c|c|c|c|c|}
\hline $\begin{array}{l}\text { Rock } \\
\text { core }\end{array}$ & $\begin{array}{l}\text { Initial } \\
\text { permeability, } \\
10^{-3} \mu \mathrm{m}^{2}\end{array}$ & $\begin{array}{l}\text { After contamination } \\
\text { permeability, } \\
10^{-3} \mu \mathrm{m}^{2}\end{array}$ & $\begin{array}{l}\text { The permeability } \\
\text { recovery value, } \%\end{array}$ & $\begin{array}{l}\text { After the resection } 0.5 \mathrm{~cm} \\
\text { contaminated end permeability, } \\
\qquad 10^{-3} \mu \mathrm{m}^{2}\end{array}$ & $\begin{array}{c}\text { The permeability recovery } \\
\text { value after the resection } 0.5 \\
\mathrm{~cm} \text { contaminated end, } \%\end{array}$ \\
\hline $1 \#$ & 292.64 & 267.12 & 91.28 & 287.14 & 98.12 \\
\hline $2 \#$ & 188.42 & 170.41 & 90.44 & 183.86 & 97.58 \\
\hline
\end{tabular}


low, and the permeability recovery value of the two rock core was high, the ability of the drilling fluid reservoir protection was better.

\section{REFERENCES}

[1] P. Reid and H. Santos, "Ultralow Invasion Drilling Fluids: A Practical Route to Reduced Wellbore Instability, Reduced Mud Losses, Wellbore Strengthening and Improved Well Productivity," 2006 SPE/IADC Indian Drilling Technology Conference and Exhibition, Mumbai, 16-18 October 2006, SPE/IADC 101329.

[2] F. Labenski, P. Reid and H. Santos, "Drilling Fluids Approaches for Control of Wellbore Instability in Fractured Formations," SPE/IADC Middle East Drilling Technology Conference \& Exhibition, Abu, 20-22 October 2003, SPE/IADC 85304.

[3] H. Santos, "Increasing Leakoff Pressure with New Class of Drilling Fluid," SPE/ISRM Rock Mechanics Conference, Irving, 20-23 October 2002, SPE/ISRM 78243.

[4] O. Friday, "Novel Wellbore Strengthening Enables Drilling of Exploration Well in a Highly Depleted Formation," Middle East Drilling Technology Conference and Exhibition, Muscat, 24-26 October 2011, SPE/IADC 148506.

[5] N. G. Mandal, U. K. Jain and B. S. Anil, "Non Damaging Drilling Fluid Enhances Bore Hole Quality and Productivity in Conventional Wells of Mehsana Asset North Cambay Basin," Indian Drilling Technology Conference and Exhibition, Mumbai, 16-18 October 2006, SPE/IADC 102128

[6] M. M. He, X. L. Pu and J. L. Su, "Research on Reservoir Protection Technology of Water Basis Film-Forming Drilling Fluid," Drilling \& Production Technology, Vol. 33, No. 5, 2010, pp. 93-95.

[7] K. E. Newsham, J. A. Rushing and P.M. Lasswell, "Use of Vapor Desorption Data to Characterize High Capillary Pressures in a Basin-Centered Gas Accumulation with Ultra-Low ConnateWater Saturations," SPE Annual Technical Conference and Exhibition, Dnver, 5-8 October 2003, SPE 84596.

[8] A. G. Arbizu, P. Reid and J. G. Moreno, "Ultra-Low Invasion Fluids: A Viable Technical Solution to Drill in Eastern Venezuela," 2009 SPE Latin American and Caribbean Petroleum Engineering Conference, Cartagena, 31 May-3 June 2009, SPE 12391.
[9] P. Reid and H. Santos, "Novel Drilling, Completion and Workover Fluids for Depleted Zones: Avoiding Losses. Formation Damage and Stuck Pipe," SPE/IADC Middle East Drilling Technology Conference \& Exhibition, Abu, 20-22 October 2003, SPE 85326.

[10] J. S. Sun, X. B. Lin and B. Zhang, "Drilling Fluid Technology Developing Tendency Predicted," Drilling Fluid \& Completion Fluid, Vol. 22, No. 1, 2005, pp. 57-59.

[11] B. Guichard, A. V. Eliokem and J. Friedheim, "An Organosoluble Polymer for Outstanding Fluid Loss Control with Minimum Formation Damage," European Formation Damage Conference, Scheveningen, 30 May-1 June 2007, SPE 107281.

[12] P. McElfresh and J. Welch, "Protecting Sand Control Screens against Solids Plugging during Installation," 2008 SPE International Symposium Drilling and Exhibition, Lafayette, 13-15 February 2008, SPE 112314.

[13] N. Morita and G. F. Fuh, "Parametric Analysis of Wellbore Strengthening Methods from Basic Rock Mechanics," SPE Annual Technical Conference and Exhibition, Denver, 30 October-2 November 2011, SPE 145765

[14] H. X. Zhang, J. N. Yan and Y. Liu, "Experimental Study of Low-Damage Drilling Fluid to Minimize Water Blocking of Low-Permeability," Petroleum Science, Vol. 6, No. 6, 2009, pp. 271-276.

[15] T. Ishizaki and K. Tani, "Experimental Study of Film Forming Effect of Water-Soluble Polymer Sampling," ISRM international Symposium 2010 and 6th Asian Rock Mechanics Symposium-Advances in Rock Engineering, New Delhi, 23-27 October 2010.

[16] D. S. Sun, F. J. Zuo and X. M. Yang, "An Ultra Low Filtration Rate Additive: Development and Application," Drilling Fluid \& Completion Fluid, Vol. 24, No. 4, 2007, pp. 21-23.

[17] J. F. Li, F. J. Zuo and P. Z. Yu, "Lab Study on Non-Invasive Drilling Fluid Additive CY-1," Petroleum Drilling Techoniques, Vol. 34, No. 1, 2006, pp. 32-35.

[18] X. D. Bai, X. L. Pu and H. Zhang, "Synthesis of Nano Filming Agent NM 1 and Its Application in Drilling Fluids," Drilling Fluid \& Completion Fluid, Vol. 24, No. 1, 2007, pp. 13-14.

[19] J. S. Sun, J. P. Tang and B. Zhang, "Methods for Testing Properties of Ultra-Low Permeable Drilling Fluid," $P e$ troleum Drilling Techoniques, Vol. 33, No. 6, 2005, pp. 25-27. 